\title{
Transurethral resection syndrome after trans- urethral resection of bladder tumours
}

The transurethral resection syndrome has not previously been described after bladder surgery. This article reports four patients who developed signs of this syndrome after transurethral resection of bladder tumours (TURB). Symptoms included abdominal pain, arterial hypotension, nausea and vomiting. There was evidence in all cases that the cause was absorption of irrigating fluid by the extravascular route. Fluid absorption was detected by ethanol in two patients and the urologist noted a perforation during the third operation. The most complicated clinical course occurred in the case where there was a delay of three hours before the diagnosis was made. Medical treatment consisted of antiemetics and volume expansion of the extracellular fluid compartment as extravasation is associated with hypovolaemia. Diuretics were not given until the circulation had been restored.

Jusqu'à maintenant, on n'a pas décrit le syndrome de la résection transuréthrale après une intervention sur la vessie. Cet article rapporte quatre observations de patients qui ont développé les signes du syndrome après une résection transuréthrale de tumeurs vésicales (RTUV). Les symptômes comprenaient de la douleur abdominale, de l'hypertension artérielle, des nausées et vomissements. Dans tous ces cas, il paraissait évident que le syndrome était causé par la réabsorption extravasculaire du liquide d'irrigation. Dans deux interventions, l'absorption de liquide a été décelée grâce à l'éthanol alors que c'est l'urologue qui a noté une perforation vésicale dans une troisième inter-

\section{Key words}

ALCOHOL: absorption, exhaled;

COMPLICATIONS:

SURGERY: urological;

SYNDROMES; TUR.

From the Department of Anaesthesiology, Huddinge

University Hospital, Huddinge, Sweden.

Address correspondence to: Dr. Robert G. Hahn,

Department of Anaesthesiology, Stockholm South Hospital, S-118 83 Stockholm, Sweden.

Accepted for publication 8th September, 1994. vention. Lévolution clinique s'est compliquée avec la lenteur à du diagnostic. Le traitement a consisté à l'administration d'un anti-émétique et, comme l'extravasation s'accompagne d'hypovolémie, au remplissage vasculaire. Les diurétiques n'ont été administrés quiaprès la restauration de la circulation.

The transurethral resection (TUR) syndrome is a complication of transurethral resection of the prostate, but it is usually not associated with transurethral resection of bladder tumours (TURB). ${ }^{1,2}$ The following four cases show that symptoms of the TUR syndrome may present after TURB. The low level of awareness of the possibility of fluid absorption facilitates misdiagnosis of this complication.

The irrigating fluid used contains glycine $1.5 \%$ and ethanol $1 \%$ but routine monitoring of fluid absorption by expired-breath tests ${ }^{3}$ was not practised during TURB when the reported operations were performed.

\section{Case reports}

\section{Case \#1}

A 70-yr-old woman (ASA II) receiving medication for hypertension underwent TURB under spinal anaesthesia that extended to the $T_{8}$ level. At the end of the 45-min resection, the systolic arterial pressure (SAP) decreased from 150 to $100 \mathrm{mmHg}$ over ten minutes despite only a small amount of bleeding. During anaesthesia and surgery the patient had been given $1,000 \mathrm{ml}$ Ringer's acetate solution by intravenous infusion. The ethanol concentration in the expired breath (EB-ethanol) was measured to determine whether fluid absorption was responsible for the hypotension. ${ }^{3}$ The EB-ethanol, expressed as the corresponding blood ethanol concentration, was $0.40 \mathrm{~g} \cdot \mathrm{L}^{-1}$ (normal value $0.01 \mathrm{~g} \cdot \mathrm{L}^{-1}$ without absorption). The operation was stopped. Physical examination revealed distension of the abdomen. The EBethanol was again $0.40 \mathrm{~g} \cdot \mathrm{L}^{-1}$ and volumetric fluid balance indicated that at least three litres had been absorbed. Infusion of $500 \mathrm{ml}$, saline solution $2 \%$ was started. The patient was transferred to the ICU for observation, where 
she experienced nausea for many hours and vomited. During this time, the SAP ranged between 110 and 150 $\mathrm{mmHg}$ and the heart rate between 80 and $110 \mathrm{bpm}$. Blood ammonia concentration was normal. She recovered without sequelae.

\section{Case \#2}

An 81-yr-old man (ASA III) suffering from rheumatoid arthritis and chronic bronchitis (body weight $32 \mathrm{~kg}$ ) underwent TURB under spinal anaesthesia that extended to the $T_{11}$ dermatome. The SAP at the start of the operation was $100 \mathrm{mmHg}$. The surgeon reported a small but incomplete perforation of the bladder wall during the 30 -min operation. The EB-ethanol was $0.15 \mathrm{~g} \cdot \mathrm{L}^{-1}$ and measurement of all irrigating fluids showed that three litres had been absorbed. The patient had been given $1,000 \mathrm{ml}$ Ringer's acetate solution and there was no bleeding.

The patient was transferred to the ICU, where a repeat exhaled-breath test showed $0.40 \mathrm{~g} \cdot \mathrm{L}^{-1}$. The SAP ranged between 65 and $100 \mathrm{mmHg}$ despite minimal bleeding. During postoperative follow-up, the patient suffered from abdominal pain, nausea and diarrhoea. His status improved during the subsequent five hours, after which he was returned to the urology clinic.

\section{Case \#3}

An 86-yr-old man (ASA II) suffering from mild angina pectoris underwent TURB under spinal anaesthesia. The average SAP was $120 \mathrm{mmHg}$ during the operation, which lasted for $35 \mathrm{~min}$, and blood loss was negligible. The urologist was called three hours after the operation as the patient complained of nausea and chest pains. There was also hypoxaemia $\left(\mathrm{SpO}_{2} 86 \%\right)$ and hypotension (SAP $80 \mathrm{mmHg}$ ). The abdomen was expanded. A central venous line was established and demonstrated low values (0 to $+2 \mathrm{mmHg}$ ).

Cystography and $x$-ray of the lungs revealed perforation of the bladder and pulmonary oedema. Volume expansion with $3.3 \%$ albumin corrected the hypotension promptly. Surgical drainage was performed $24 \mathrm{hr}$ after TURB when the patient had developed peritonitis. Clear fluid, $1.2 \mathrm{~L}$ was drained from the peritoneal cavity. During this operation, the patient required blood and albumin transfusions and ephedrine to maintain haemodynamic stability. The subsequent course included several attacks of angina pectoris and atrial fibrillation. The serum creatinine concentration increased gradually from 109 $\mu \mathrm{mol} \cdot \mathrm{L}^{-1}$ before the operation to $212 \mu \mathrm{mol} \cdot \mathrm{L}^{-1}$ one week postoperatively. At this time, the patient was discharged from hospital. However, he was readmitted four days later because of urological sepsis, from which he recovered.

\section{Case \#4}

An 81-yr-old woman (ASA II) suffering from Parkinson's disease underwent TURB under general anaesthesia. During the operation, $500 \mathrm{ml}$ glucose $5 \%$ was given $i$. Perforation of the bladder was suspected at the end of the procedure because the irrigating fluid returns became smaller. During the subsequent $24 \mathrm{hr}$, the patient was extremely exhausted and suffered from intermittent abdominal pain, dyspnoea, sweating, vomiting and mild nausea. There was hypertension $(200 / 100 \mathrm{mmHg})$ and tachycardia $(100 \mathrm{bpm})$ between three and six hours after the TURB. The patient reported increased dyspnoea during the next two days, and this was treated with theophylline and additional furosemide. A chest $x$-ray demonstrated bilateral pleural effusions. The patient slowly regained physical strength and was discharged from the hospital one week later.

\section{Discussion}

These fours cases show that a mild to moderately severe TUR syndrome can develop after TURB. In all the patients, there was evidence that absorption of electrolytefree irrigating fluid had occurred during the operation.

Fluid absorption may be followed by two different patterns of dilutional changes. The most common results in immediate dilutional hyponatraemia and corresponds to absorption directly into the bloodstream. ${ }^{1,3}$ The less common pattern consists of delayed hyponatraemia and occurs after perforation of the prostatic capsule or of the bladder. 5,6 The four cases reported here all showed this extravascular pattern of serum sodium changes (Table I). The irrigating fluid had probably accumulated in the peritoneal cavity through a perforation of the bladder, although this was only confirmed by $x$-ray and reoperation in one of the patients.

Symptoms of intravascular absorption include restlessness, hypertension, nausea and confusion. Intraperitonal absorption gives rise to a somewhat different clinical picture. Abdominal pressure or pain, which may radiate to the shoulders, may be the first symptom. ${ }^{6-9}$ Hypotension and abdominal swelling are often apparent at the end of the operation, and patients with hypotension are at risk of developing oliguria. ${ }^{5}$ Nausea, vomiting, dyspnoea and pulmonary oedema are general signs of fluid absorption, but the onset is later after uptake by the extravascular than by the intravascular route.

Diffusion of water and solutes probably plays a key role in the pathophysiology of the circulatory symptoms. Electrolytes enter the extravasated pool of fluid, which promotes loss of water from the extravascular space. In contrast, the irrigant water follows the bulk of absorbed glycine and ethanol, which equilibrate with the total body 
TABLE I The blood haemoglobin (B-Hb) and serum sodium (S-Na) concentrations before and after transurethral resection of bladder tumours in four patients.

\begin{tabular}{|c|c|c|c|c|c|c|c|c|}
\hline & \multicolumn{2}{|l|}{ Case 1} & \multicolumn{2}{|l|}{ Case 2} & \multicolumn{2}{|l|}{ Case 3} & \multicolumn{2}{|l|}{ Case 4} \\
\hline & $\begin{array}{l}B-H b \\
\left(g \cdot L^{-1}\right)\end{array}$ & $\begin{array}{l}S-\mathrm{Na} \\
\left(\mathrm{mmol} \cdot \mathrm{L}^{-1}\right)\end{array}$ & $\begin{array}{l}B-H b \\
\left(g \cdot L^{-1}\right)\end{array}$ & $\begin{array}{l}\mathrm{S}-\mathrm{Na} \\
\left(\mathrm{mmol} \cdot L^{-1}\right)\end{array}$ & $\begin{array}{l}B-H b \\
\left(g \cdot L^{-t}\right)\end{array}$ & $\begin{array}{l}S-\mathrm{Na} \\
\left(\mathrm{mmol} \cdot L^{-1}\right)\end{array}$ & $\begin{array}{l}B-H b \\
\left(g \cdot L^{-I}\right)\end{array}$ & $\begin{array}{l}S-\mathrm{Na} \\
\left(\mathrm{mmol} \cdot \mathrm{L}^{-1}\right)\end{array}$ \\
\hline Before TURB & 124 & 139 & 117 & 141 & 116 & 136 & 131 & 142 \\
\hline End of TURB & 127 & 136 & 114 & 127 & - & - & 146 & 132 \\
\hline $3 \mathrm{hr}$ after & 134 & 133 & - & 123 & 121 & 127 & - & 125 \\
\hline $6 \mathrm{hr}$ after & 133 & 131 & 122 & 128 & - & - & 154 & 130 \\
\hline
\end{tabular}

TABLE II Treatment given during the first $12 \mathrm{hr}$ after fluid absorption had become apparent. All patients were also given opioid analgesics to alleviate abdominal pain and oxygen.

\begin{tabular}{|c|c|c|c|c|}
\hline & Case I & Case 2 & Case 3 & Case 4 \\
\hline Ephedrine (mg) & - & $10+5$ & $5+5+5+10$ & - \\
\hline Furosemide (mg) & $20+10+10+10$ & $10+10+10+10$ & $40+20+20+20$ & $20+20+20$ \\
\hline Metoclopramide (mg)* & $10+5+5$ & 10 & $5+5$ & - \\
\hline Ringer's acetate (ml) & 500 & 2000 & 1000 & 1000 \\
\hline - Na content (mmol) & 145 & 420 & 130 & 210 \\
\hline Glucose $5 \%$ & 2000 & 1000 & 2000 & 2000 \\
\hline - Na content (mmol) & 100 & 80 & 80 & 80 \\
\hline Albumin $3.3 \%(\mathrm{ml})$ & - & - & 1000 & 500 \\
\hline Antibiotics & Bactrim $\dagger$ & Bactrim $\dagger$ & Bactrim $\dagger$ and gentamicin & - \\
\hline
\end{tabular}

*Used as an antiemetic.

†Contains trimethoprim and sulphamethoxazole.

water. This difference in distribution between the solutes that exchange over the peritoneal membrane increases the ratio of intra- to extracellular water. The paradoxical effect of the fluid overload is hypovolaemia, which has been confirmed clinically, ${ }^{5,7,8}$ and in a series of experiments in dogs. ${ }^{10}$ All four patients in this report exhibited haemoconcentration, indicating that blood volume was low (Table I).

The existence of the TUR syndrome after TURB suggests a need for assessment of the fluid balance during these operations. When the irrigating fluid contains $1 \%$ ethanol, a breath test facilitates early diagnosis. ${ }^{3}$ In the first two of the reported cases, the ethanol test showed that fluid absorption had occurred. However, the fairly low EB-ethanol levels were misleading as the published nomogram ' for converting EB-ethanol into the volume of irrigant absorption is intended for the intravascular type of fluid absorption. When there is extravasation, the EB-ethanol concentration increases more slowly and reaches a plateau $20 \mathrm{~min}$ after the absorption, which is illustrated in Case \#2. Furthermore, the plateau is only one-third of the value that would be obtained if the same amount of fluid was absorbed by the intravascular route. ${ }^{4}$ In Case \#1, the EB-ethanol level corresponded to an ab- sorption of about $1.3 \mathrm{~L}$ by the intravascular ${ }^{1}$ or four litres by the extravascular route, ${ }^{4}$ but the unchanged EBethanol level after irrigation with ethanol was discontinued is diagnostic of extravasation. Awareness of the extravascular pattern of ethanol changes is essential when using ethanol concentration as an indication of absorption, although the intravascular pattern is ten times more common during transurethral resection of the prostate, for which the method was originally developed."

Medical treatment is based on the understanding that extravasation produces a hypovolaemic condition (Table II). The pool of irrigating fluid is not available for diuretic therapy early on after extravasation, and such treatment may aggravate the hypotension. Furosemide should be withheld until the circulation has been restored by intravenous infusion of a colloid solution, additional electrolytes and, possibly, a vasoconstrictor. ${ }^{5}$ Careful monitoring of the urine output is mandatory. Surgical drainage reduces morbidity and mortality from extravasation during TURP, ${ }^{12}$ but seems to be necessary only after massive absorption with severe circulatory symptoms. ${ }^{5,6}$

In conclusion, symptoms of the TUR syndrome resulting from extravascular absorption of irrigating fluid can occur after TURB and suggest that fluid balance 
should be monitored in extensive TURB operations, either by EB-ethanol or by repeated measurement of the volumetric fluid balance.

\section{References}

1 Hahn RG. The transurethral resection syndrome. Acta Anaesthesiol Scand 1991; 35: 557-67.

2 Rentzhog $L$, Olsson $J$. Risk of irrigant absorption during TUR of bladder tumors? Scand J Urol Nephrol 1992; 26 (suppl. 147): 20-1.

3 Hahn R, Mjöberg M. Immediate detection of irrigant absorption during transurethral prostatecomy: case report. Can J Anaesth 1989; 36: 86-8.

4 Hahn RG. Ethanol monitoring of extravascular absorption of irrigating fluid. Br J Urol 1993; 72: 766-9.

5 Hahn RG. Transurethral resection syndrome from extravascular absorption of irrigating fluid. Scand J Urol Nephrol 1993; 27: 387-94.

6 Weber S, Acuff JH, Mazloomdoost M, Kirimli BI. Transurethral prostatectomy complicated by intraperitoneal extravasation of irrigating fluid. Can J Anaesth 1987; 34: 193-5.

7 Montesinos Baillo A, Banuis Gassol J, Palou Redorta J, Nogueron Castro M, Macias Giménez N. Physiopathology and surgical treatment of extravasated peritoneal fluid after transurethral resection. Eur Urol 1984; 10: 183-6.

8 Marmar JL, Allen SD. The transurethral resection reaction secondary to intraperitoneal extravasation of irrigating solution. J Urol 1970; 104: 457-8.

9 Hahn RG, Olsson J. Intraperitoneal absorption of irrigating fluid during endometrial resection. Acta Obstet Gynecol Scand 1993; 72: 402-5.

10 Mahoney SA, Forsythe WE III, Persky L. Intraperitoneal extravasation of irrigant solutions. J Urol 1965: 94: 276-81.

II Hahn RG, Ekengren J. Patterns of irrigating fluid absorption during transurethral resection of the prostate as indicated by ethanol. J Urol 1993; 149: 502-6.

12 Holtgrewe $H L$, Valk WL. Factors influencing the mortality and morbidity of transurethral prostatectomy: a study of 2,015 cases. J Urol 1962; 87: 450-9. 